\title{
BMJ Open Protocol of a retrospective, multicentre observational study on hyperthermic intrathoracic chemotherapy in Germany
}

\author{
Till Markowiak (10 , ${ }^{1}$ Michael Koller, ${ }^{2}$ Florian Zeman, ${ }^{2}$ Gunnar Huppertz, ${ }^{2}$ \\ Hans-Stefan Hofmann, ${ }^{1}$ Michael Ried, ${ }^{1}$ HITOC Study Group
}

To cite: Markowiak T, Koller M, Zeman F, et al. Protocol of a retrospective, multicentre observational study on hyperthermic intrathoracic chemotherapy in Germany. BMJ Open 2020;10:e041511. doi:10.1136/ bmjopen-2020-041511

- Prepublication history for this paper is available online. To view these files, please visit the journal online (http://dx.doi. org/10.1136/bmjopen-2020041511).

Received 10 June 2020 Revised 21 June 2020 Accepted 22 June 2020

Check for updates

(c) Author(s) (or their employer(s)) 2020. Re-use permitted under CC BY-NC. No commercial re-use. See rights and permissions. Published by BMJ.

${ }^{1}$ Department of Thoracic Surgery, Universitätsklinikum Regensburg, Regensburg, Bayern, Germany

${ }^{2}$ Center for Clinical Studies, Universitätsklinikum Regensburg, Regensburg, Bayern, Germany

Correspondence to Professor Michael Ried; michael.ried@ukr.de

\section{ABSTRACT}

Introduction Objective of the 'German hyperthermic intrathoracic chemotherapy (HITOC) study' is to evaluate the HITOC as additional treatment after surgical cytoreduction for malignant pleural tumours. Even though HITOC is applied with increasing frequency, there is no standardised therapy protocol concerning the technique of HITOC, the selection as well as dosage of chemotherapeutic agents and perioperative management in order to provide a safe and comparable, standardised treatment regime.

Methods and analysis This trial is a retrospective, multicentre observational study, which is funded by the German Research Foundation. Approximately 300 patients will be included. Four departments of thoracic surgery, which are performing the most HITOC procedures in Germany, are contributing to this study: Center for Thoracic Surgery at the University Hospital Regensburg, Thoracic Clinic Heidelberg of the University of Heidelberg, Center for Thoracic Surgery of the Hospital University of Munich and the Department of Thoracic Surgery at the University Hospital Freiburg. All patients who underwent surgical cytoreduction and subsequent HITOC at one of the four centres between starting the HITOC programme in 2008 and December 2019 will be included. Information on the performed HITOC will be obtained, focusing on the technique as well as the applied perfusion solution including the chemotherapeutic agent. Furthermore, parameters of the patient's postoperative recovery will be analysed to determine 30-day morbidity and mortality. Ethics and dissemination The approvals by the local ethics committee of the respective clinic and the three participating clinics have been obtained. The results will be presented in conferences and published in a peerreviewed journal.

Trial registration number German Clinical Trials Registry (DRKS00015012; Pre-results).

\section{INTRODUCTION}

Hyperthermic intrathoracic chemotherapy (HITOC) is a local, intraoperative perfusion of the thoracic cavity with a chemotherapeutic agent after surgical cytoreduction of malignant pleural tumours. The HITOC represents an additional therapeutic option in a multimodality treatment concept especially for patients with malignant pleural

\section{Strengths and limitations of this study}

The results of this retrospective, multicentre study should allow a better standardisation of the hyperthermic intrathoracic chemotherapy (HITOC) procedure including perioperative safety measures and also validate the existing clinical experience.

- In the long term, it could be the basis for survival analyses and further prospective studies.

- Due to the retrospective nature of our study, the implementation of HITOC was not uniform, which affects the analysis of 30-day morbidity and mortality.

- To the best of our knowledge, this study will represent the largest cohort of patients with surgical cytoreduction and HITOC.

mesothelioma (MPM), thymic tumours with pleural spread (stage IVa) and even in highly selected patients with pleural carcinosis. ${ }^{1}{ }^{2}$ The spreading growth pattern of these malignant tumours along the pleura impairs a microscopically complete resection, and small residues of the tumour often lead to local recurrence. ${ }^{2}$ With the application of the HITOC after macroscopic complete pleural tumour resection, it is expected to obtain better local tumour control, and thereby improve progression-free as well as overall survival. ${ }^{2-4}$ The few existing case series or single-centre retrospective studies in patients with MPM and thymic tumours have shown some encouraging results in this regard. ${ }^{25-9}$ However, a prospective study showing an advantage in survival does not yet exist.

A survey of the German Society for Thoracic Surgery on the application of HITOC confirmed that approximately 350 HITOC procedures have already been performed in Germany from 2008 to 2017. Most of the procedures were conducted at University Thoracic Surgery Centers in Munich, Heidelberg, Freiburg, Regensburg and Cologne (Witten-Herdecke). ${ }^{10}$ 


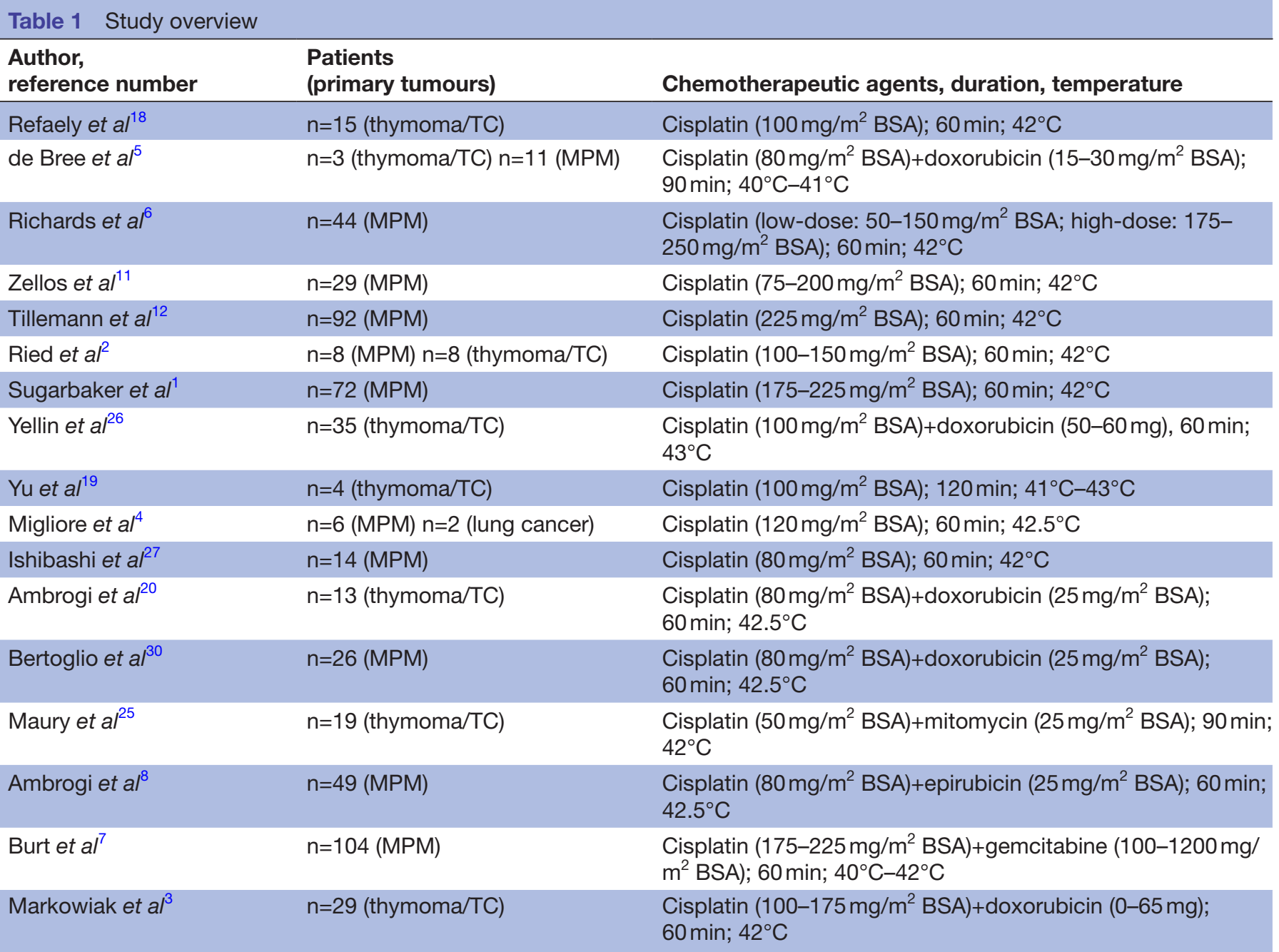

BSA, body surface area; MPM, malignant pleural mesothelioma; TC, thymic carcinoma.

Although HITOC is performed routinely in some experienced departments of thoracic surgery in Germany, only feasibility studies, case series and retrospective studies with small numbers of patients have been published so far evaluating perioperative management, technique, the selection and dosage of chemotherapeutic agents and postoperative complications ${ }^{111}{ }^{12}$ (table 1 ). There is no standardised procedure of HITOC concerning the administration of chemotherapeutic agents, the dosage of the drugs, duration and temperature of the perfusion as well as the perioperative management of these patients including safety measures for the personal. As a result, clinics performing HITOC follow internationally reported experiences and developed individual protocols. ${ }^{10}$ In 2019, a clinical practice guideline on HITOC within the guideline system of the Association of the Scientific Medical Societies in Germany was published. Due to the lack of empirical data, this guideline was based on an expert consensus (so called S1-guideline). The group of experts agreed on the key aspects of applying HITOC in thoracic surgery (table 2$){ }^{13}$
Before performing the HITOC, all patients underwent surgical cytoreduction of the pleural tumour. Therefore, pleurectomy/decortication $(\mathrm{P} / \mathrm{D})$, extended $\mathrm{P} / \mathrm{D}$ $(\mathrm{eP} / \mathrm{D})$ with partial and/or complete resection of the pericardium and/or diaphragm or extrapleural pneumonectomy (EPP) are carried out to achieve a macroscopic complete resection whenever possible. ${ }^{14}$ The outcome of lung-saving procedures $(\mathrm{P} / \mathrm{D}$ and $\mathrm{eP} / \mathrm{D})$ turned out to be equivalent to EPP with significantly less complications, so that these procedures should preferably be performed. ${ }^{8}$

Usually HITOC and tumour resection are performed in the same session. Apical inflow and basal outflow drainages are placed in the thoracic cavity. The following perfusion can be carried out with an open (before wound closure) or closed (after wound closure) chest, while the procedure on the closed chest is more common. Its advantage is that no cytostatic agent can leak out of the thoracic cavity during circulation, which would be a safety risk for the practitioner. ${ }^{710}$ The drainages are then connected to an external perfusion system. A stable circulation is established with a priming-volume, and the perfusion solution is heated to a targeted temperature of $40^{\circ} \mathrm{C}-43^{\circ} \mathrm{C}^{915}$ The 


\begin{tabular}{|c|c|}
\hline & Content; consensus strength \\
\hline Nomenclature & $\begin{array}{l}\text { Hyperthermic intrathoracic } \\
\text { chemotherapy; } 100 \%\end{array}$ \\
\hline Technique & $\begin{array}{l}\text { One session; } 100 \% \\
\text { Closed thorax; } 100 \% \\
\text { Temperature of } 42^{\circ} \mathrm{C} \text { on the outflow } \\
\text { drainage; } 100 \% \\
\text { Duration of } 60 \mathrm{~min} ; 100 \%\end{array}$ \\
\hline $\begin{array}{l}\text { Chemotherapeutic } \\
\text { agents }\end{array}$ & $\begin{array}{l}\text { Application of cisplatin; } 100 \% \\
\text { Maximum dosage of } 225 \mathrm{mg} / \mathrm{m}^{2} \\
\text { BSA; } 100 \% \\
\text { Dosage between } 150 \mathrm{mg} / \mathrm{m}^{2} \text { and } \\
175 \mathrm{mg} / \mathrm{m}^{2} \text { BSA; } 100 \%\end{array}$ \\
\hline $\begin{array}{l}\text { Perioperative } \\
\text { management }\end{array}$ & $\begin{array}{l}\text { Perioperative fluid balancing and } \\
\text { forced diuresis; } 100 \% \\
\text { Drug-based nephroprotection may } \\
\text { be considered; } 100 \% \\
\text { Safety management including } \\
\text { protective clothing of the personnel } \\
\text { and disposal of drain fluids; } 100 \%\end{array}$ \\
\hline Indications & $\begin{array}{l}\text { Malignant pleural mesothelioma; } \\
100 \% \\
\text { Stage IVa thymoma; } 100 \% \\
\text { - Secondary pleural carcinosis; } 100 \%\end{array}$ \\
\hline
\end{tabular}

BSA, body surface area.

chemotherapeutic agents are added to the perfusate and the circulation is performed between $60 \mathrm{~min}$ and $120 \mathrm{~min}$. Subsequently, the perfusion solution is passively drained.

This retrospective, multicentre study will provide the first-time opportunity to enrol a substantial number of study participants from experienced German centres regarding HITOC to validate the clinical experience of the individual centres and possibly to form the basis for a standardised procedure with an adequate perioperative management in patients who underwent HITOC. In the long term, this database might be used for survival analyses with respect to the different tumour entities and may serve to design a prospective study.

\section{METHODS AND ANALYSIS \\ Study design}

This is a retrospective, multicentre observational study to evaluate HITOC at university thoracic surgery clinics with the most performed operations including HITOC in Germany. The participating clinics include the Thoracic Surgery Center Regensburg (University Hospital Regensburg, Hospital Barmherzige Brüder Regensburg), the Department of Thoracic Surgery, Thoracic Clinic Heidelberg (University of Heidelberg), the Department of Thoracic Surgery, Medical Center, University of Freiburg
Table 3 Inclusion and exclusion criteria

\begin{tabular}{|c|c|}
\hline Inclusion criteria & Exclusion criteria \\
\hline - Age $\geq 18$ years & - Treatment without HITOC \\
\hline - Malignant pleural tumour & $\begin{array}{l}\text { HITOC without surgical } \\
\text { cytoreduction }\end{array}$ \\
\hline \multicolumn{2}{|l|}{$\begin{array}{l}\text { Surgical cytoreduction and } \\
\text { HITOC }\end{array}$} \\
\hline $\begin{array}{l}\text { Treatment period: } \\
\text { 2008-2019 }\end{array}$ & \\
\hline
\end{tabular}

HITOC, hyperthermic intrathoracic chemotherapy.

and the Thoracic Surgery Center Munich, Hospital of the University of Munich (Ludwig Maximilians University, Campus Großhadern; Asklepios Lung Clinic Gauting). Estimating the number of patients of each participating clinic at the time of designing, this study resulted in a total number of approximately 350 patients in the period between January 2008 and December 2019 and who could be retrospectively included in this study. This will represent the largest cohort of patients who received HITOC compared with the recent international literature (table 1$){ }^{9}$

\section{Inclusion and exclusion criteria}

The study will examine patients with malignant pleural tumours who received HITOC after surgical cytoreduction between beginning of the HITOC programme in 2008 and the end of December 2019 at all study centres. Patients without HITOC or without surgical cytoreduction will not be included (table 3). Informed consent is not an eligibility criterion because data will be processed in a pseudonymised manner in accordance with European Union General Data Protection Regulation (EUGDPR) and Bavarian Hospital Law (BayKrG).

\section{Study endpoints}

This study aims at quality assurance and evaluation of HITOC after surgical cytoreduction at the thoracic surgical university hospitals with most experience with HITOC in Germany. For this broad assessment, a compound of endpoints was defined as shown in box 1 .

Central element of the study will be the evaluation of parameters concerning the implementation of HITOC.

\section{Box 1 Study endpoints (quality assurance and} implementation of intraoperative HITOC after surgical cytoreduction)

Study endpoints

Dosing of the intrathoracic chemotherapeutic agent.

- Postoperative renal failure (dependence on cisplatin dosage).

30-day morbidity and mortality.

- Development of the technique, perioperative management and complication spectrum over time of HITOC.

HITOC, hyperthermic intrathoracic chemotherapy. 


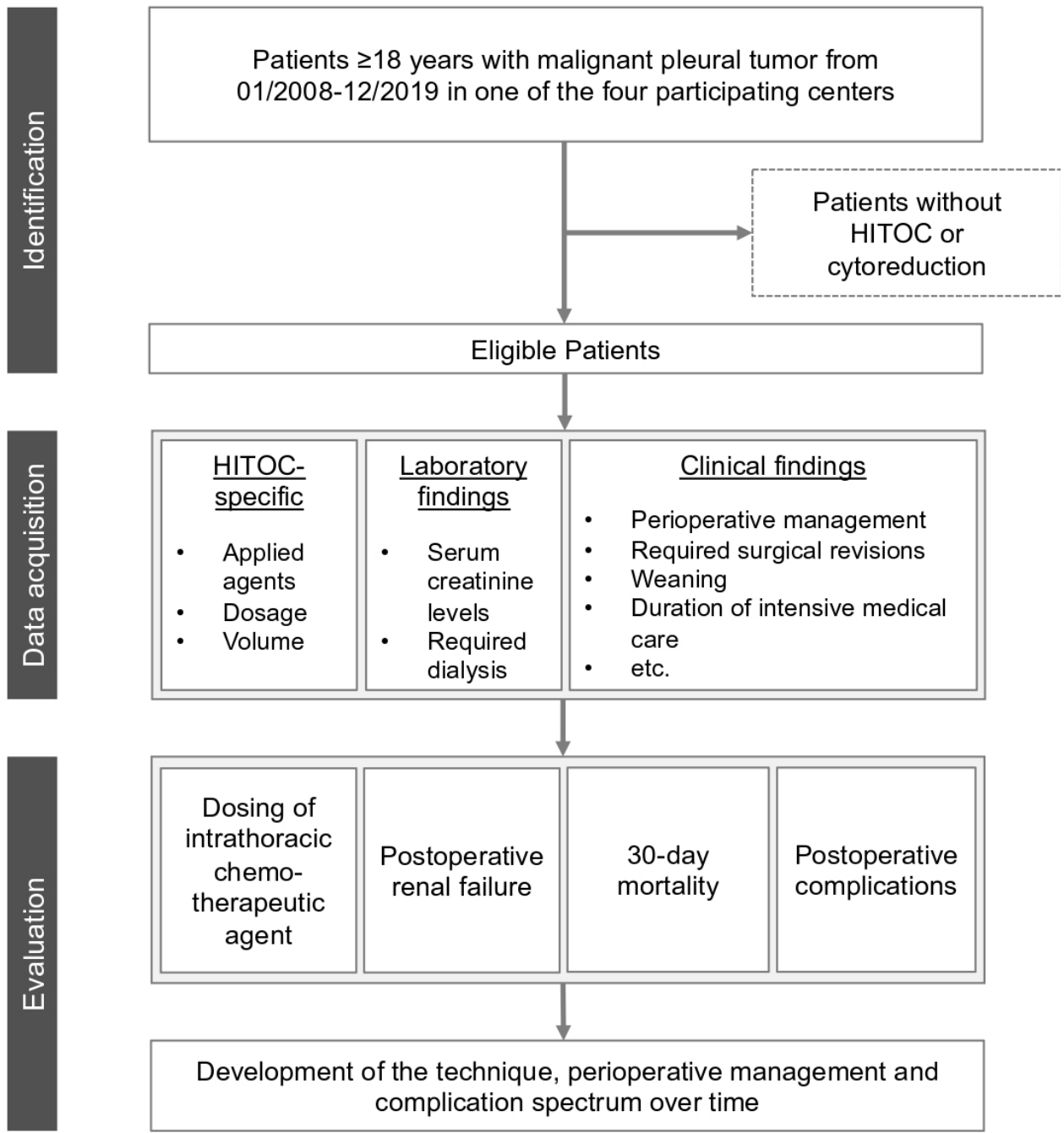

Figure 1 Flowchart of the study design. HITOC, hyperthermic intrathoracic chemotherapy.

In particular, the selection of chemotherapeutic agents by the respective clinics will be assessed by showing which and how often certain combinations and dosages were used at leading German clinics in this field, since the approach varies internationally (table 1 ). In this regard, the association of the administered cisplatin dosage with the occurrence and severity (according to the Kidney Disease Improving Global Outcomes (KDIGO) classification) of postoperative renal insufficiency will be analysed. Also the incidence and severity (according to the ClavienDindo classification) as well as the spectrum of postoperative complications after HITOC will be determined. To further evaluate the safety of the procedure, 30-day mortality will be another element of the assessment. Finally, the development of this procedure in Germany concerning the technique, perioperative management and safety over a time span of approximately 11 years will be demonstrated (figure 1).

\section{Documentation and database}

After identifying all patients who meet all criteria shown in table 3 , data will be documented in an electronic database. In this database, information on the performed surgery and additional HITOC will be obtained, focusing on the technique as well as the applied perfusion solution. Therefore, participating clinics will enter parameters regarding the patient characteristics (age, Eastern Cooperative Oncology Group (ECOG) stage, American Society of Anaesthesiologists (ASA) stage, tumour entity, tumour stage, date of first diagnosis), performed surgery (localisation, extend of surgical cytoreduction, complications), HITOC (combination and dosage of chemotherapeutics, perfusion volume, temperature, flow rate, duration of chemotherapy perfusion, complications) and perioperative management (weaning, fluid balancing, care on the intensive care unit). Data from the postoperative period (30-day morbidity) also include complications assigned to the Clavien-Dindo classification with special respect to postoperative renal insufficiency, required surgical revisions, duration of intensive medical care, hospitalisation and 30-day mortality. ${ }^{16}$ In addition, first data regarding progression-free and overall survival are warranted to be analysed (box 2). 
Box 2 Overview of data collection with respect to subgroups

Subgroups of data collection

- Demographic data.

- Physical examination.

- Performance status.

- Tumour specific data.

- Surgery specific data (intraoperative, postoperative).

- HITOC specific data.

- Renal function.

- Information on hospitalisation.

- Follow-up.

HITOC, hyperthermic intrathoracic chemotherapy.

\section{Data management}

The Center for Clinical Studies (ZKS) of the University Medical Center Regensburg is establishing a web-based, central and uniform database, using a common Clinical Database Management System. This system provides the capability to perform major data management activities within a consistent, auditable, integrated and EU-GDPR compliant environment. Data quality checks (regarding data ranges, validity and consistency) will be carried out regularly. In case of necessary corrections or existing data inconsistencies, a data manager will generate data queries consecutively. All data entries will be routinely recorded via audit trail as well as data modifications and data corrections.

\section{Statistical analyses}

Subsequently, the statistical data evaluation of the study is also carried out by the ZKS of the University Hospital Regensburg.

Patient characteristics, quality assurance parameters and evaluation of HITOC after surgical cytoreduction (box 1) will be summarised descriptively, using absolute and relative frequencies for categorical data and mean, $\mathrm{SD}$, median, IQR, minimum and maximum for metric data.

Risk factors (eg, HITOC parameters) for 30-day mortality, in-hospital mortality and postoperative complications will be assessed by using binary logistic regression models. With regard to all outcome measurements, reference values for optimal HITOC parameters will be provided. The level of significance will be set at $5 \%$ for all statistical tests.

The results of this retrospective study are intended to contribute to a standardisation of the perioperative procedure including safety measurements. To establish quality assurance in patients with HITOC, benchmarks are to be defined on the basis of the study. The rate of lung-sparing resections as well as the rate of postoperative renal insufficiency, wound infections as well as the length of hospital stay after surgical cytoreduction including HITOC and the 30-day mortality will be determined and thus provide reference for clinics performing this combined procedure.

\section{Ethics and dissemination}

The study was funded by the German Research Foundation (Deutsche Forschungsgemeinschaft-DFG; GZ: RI 2905/3-1) and will be supported for 12 months after its start in January 2020. The trial is registered in the German Register of Clinical Studies (date of registration: 03 August 2018). The approvals by the local ethics committee of the respective clinic and the three participating clinics have been obtained (reference number University Regensburg: 18-1119-104). Each patient will be assigned an identification number for pseudonymisation. The study ends regularly in December 2020 when the study parameters have been evaluated and published. The results are planned to be published in a peer-reviewed journal.

\section{Patient and public involvement}

In this study, patients or the public were not involved in the design, conduct, reporting or dissemination of research.

\section{DISCUSSION}

There are different approaches in the international literature regarding the implementation and perioperative management of HITOC after surgical cytoreduction. ${ }^{9} \mathrm{~A}$ common standard for the procedure of HITOC does not yet exist, so that clinics performing this procedure orientate their protocols towards a small number of studies with often few participants (table 1).

The available single-centre studies demonstrated that the rate of complications could be acceptable with an appropriate perioperative management. ${ }^{1112}$ To perform HITOC safely and keep HITOC-specific complications low, adequate perioperative management and an interdisciplinary approach are essential, especially between surgery, anaesthesia and intensive care. ${ }^{17}$

In the published research, cisplatin is always part of the perfusion solution. However, the dose administered varies, but usually it is applied in doses lower than $175 \mathrm{mg} / \mathrm{m}^{2}$ body surface area (BSA) (table 1). ${ }^{1018-20}$ The application of higher doses of cisplatin seems to be associated with better overall survival, but also might cause more complications. Our study group described that the cisplatin concentration in patient serum increases to only about $2 \%$ of the intrathoracic concentration, although if the cisplatin dosage is increased up to $150 \mathrm{mg} / \mathrm{m}^{2}$ BSA. $^{621}$ As a result, much higher concentrations can be achieved locally in the tissue than with systemic administration. ${ }^{15}$ However, high intrathoracic concentrations lead to an increased incidence of postoperative complications (eg, renal insufficiency), for which reason the maximum tolerable dose of cisplatin was identified at $225 \mathrm{mg} / \mathrm{m}^{2}$ BSA. $^{6}$ Concerning postoperative renal insufficiency, the use of protective measures such as nephroprotective agents and fluid balancing may have a preventive effect. ${ }^{22}$ First introduced by Sugarbaker et al in HITOC, it is currently also being practised in a few more studies. ${ }^{62}$ 
The application of a second chemotherapeutic agent is also heterogeneous. The considerations of applied agents were guided by the experience in systemic therapy. Superiority over systemic cisplatin monotherapy has been demonstrated in both patients with MPM and thymoma. ${ }^{2324}$ In some clinics, cisplatin is combined with doxorubicin, epirubicin, gemcitabine or mitomycin, whereas other clinics use cisplatin alone. ${ }^{51825}$

Another factor where the protocols differ in international compare is the target temperature of the chemotherapeutic solution. During perfusion, it is constantly measured using two probes at the inflow and outflow drainages. ${ }^{6}$ It has been shown that the penetration depth of cisplatin into the tissue increases with the temperature of the intrathoracic solution. Applied temperatures of $40^{\circ} \mathrm{C}-43^{\circ} \mathrm{C}$ are described in the literature. ${ }^{126-28}$ Intrapleural temperatures above $43^{\circ} \mathrm{C}$ are supposed with an increased risk of pulmonary oedema and should therefore be avoided. ${ }^{29}$ Also, high temperatures of the perfusate lead to an increased risk of systemic hyperthermia. ${ }^{17}$ Regarding the optimal duration of perfusion, only little research exists and thus varies between $60 \mathrm{~min}$ and 120 min. $^{19} 25$

\section{Conclusion}

In summary, the German HITOC study will include the biggest study population with surgical cytoreduction and HITOC since now. It will retrospectively evaluate the additional HITOC procedure with main respect to quality assurance and it will support a standardisation of the procedure. Results are expected in 2021.

\section{Trial status}

At the time of manuscript submission, database is finished and data collection started in April 2020. The following analyses are planned to be completed by the end of 2020 .

Collaborators HITOC Study Group:Hauke Winter; Martin Eichhorn; Laura Klotz; Rudolf Hatz; Julia Zimmermann; Julia Kovacs; Bernward Passlick; Severin Schmid; Mohamed Hassan.

Contributors TM and MR wrote the manuscript. FZ, GH and MK proved the manuscript regarding the study design and the described statistical analysis. $\mathrm{H}-\mathrm{SH}$ and all collaborators of the HITOC Study Group revised the manuscript critically. All authors approved the final version of the manuscript.

Funding This work was supported by the German Research Foundation, Kennedyallee 40, 53170, Bonn, Germany (Grant number GZ: RI 2905/3-1).

\section{Competing interests None declared.}

Patient and public involvement Patients and/or the public were not involved in the design, or conduct, or reporting or dissemination plans of this research.

\section{Patient consent for publication Not required.}

Provenance and peer review Not commissioned; peer reviewed for ethical and funding approval prior to submission.

Open access This is an open access article distributed in accordance with the Creative Commons Attribution Non Commercial (CC BY-NC 4.0) license, which permits others to distribute, remix, adapt, build upon this work non-commercially, and license their derivative works on different terms, provided the original work is properly cited, appropriate credit is given, any changes made indicated, and the use is non-commercial. See: http://creativecommons.org/licenses/by-nc/4.0/.

\section{ORCID iD}

Till Markowiak http://orcid.org/0000-0002-5364-6206

\section{REFERENCES}

1 Sugarbaker DJ, Gill RR, Yeap BY, et al. Hyperthermic intraoperative pleural cisplatin chemotherapy extends interval to recurrence and survival among low-risk patients with malignant pleural mesothelioma undergoing surgical macroscopic complete resection. $J$ Thorac Cardiovasc Surg 2013;145:955-63.

2 Ried M, Potzger T, Braune N, et al. Cytoreductive surgery and hyperthermic intrathoracic chemotherapy perfusion for malignant pleural tumours: perioperative management and clinical experience. Eur J Cardiothorac Surg 2013;43:801-7.

3 Markowiak T, Neu R, Ansari MKA, et al. Surgical cytoreduction and HITOC for thymic malignancies with pleural dissemination. Thorac Cardiovasc Surg 2019:1700883.

4 Migliore M, Calvo D, Criscione A, et al. Cytoreductive surgery and hyperthermic intrapleural chemotherapy for malignant pleural diseases: preliminary experience. Future Oncol 2015;11:47-52.

5 de Bree E, van Ruth S, Baas P, et al. Cytoreductive surgery and intraoperative hyperthermic intrathoracic chemotherapy in patients with malignant pleural mesothelioma or pleural metastases of thymoma. Chest 2002;121:480-7.

6 Richards WG, Zellos L, Bueno R, et al. Phase I to II study of pleurectomy/decortication and intraoperative intracavitary hyperthermic cisplatin lavage for mesothelioma. J Clin Oncol 2006;24:1561-7.

7 Burt BM, Richards WG, Lee H-S, et al. A phase I trial of surgical resection and intraoperative hyperthermic cisplatin and gemcitabine for pleural mesothelioma. J Thorac Oncol 2018;13:1400-9.

8 Ambrogi MC, Bertoglio P, Aprile V, et al. Diaphragm and lungpreserving surgery with hyperthermic chemotherapy for malignant pleural mesothelioma: a 10-year experience. J Thorac Cardiovasc Surg 2018;155:1857-66.

9 Zhou H, Wu W, Tang X, et al. Effect of hyperthermic intrathoracic chemotherapy (HITHOC) on the malignant pleural effusion: a systematic review and meta-analysis. Medicine 2017;96:e5532.

10 Ried M, Hofmann HS, Dienemann H, et al. Implementation of Hyperthermic Intrathoracic Chemotherapy (HITHOC) in Germany]. Zentralbl Chir 2018.

11 Zellos L, Richards WG, Capalbo L, et al. A phase I study of extrapleural pneumonectomy and intracavitary intraoperative hyperthermic cisplatin with amifostine cytoprotection for malignant pleural mesothelioma. J Thorac Cardiovasc Surg 2009;137:453-8.

12 Tilleman TR, Richards WG, Zellos L, et al. Extrapleural pneumonectomy followed by intracavitary intraoperative hyperthermic cisplatin with pharmacologic cytoprotection for treatment of malignant pleural mesothelioma: a phase II prospective study. J Thorac Cardiovasc Surg 2009;138:405-11.

13 Ried M, Eichhorn M, Winter H, et al. [Expert Recommendation for the Implementation of Hyperthermic Intrathoracic Chemotherapy (HITOC) in Germany]. Zentralbl Chir 2020;145:89-98.

14 Rusch V, Baldini EH, Bueno R, et al. The role of surgical cytoreduction in the treatment of malignant pleural mesothelioma: meeting summary of the International mesothelioma interest group Congress, September 11-14, 2012, Boston, mass. J Thorac Cardiovasc Surg 2013;145:909-10.

15 Ried M, Lehle K, Neu R, et al. Assessment of cisplatin concentration and depth of penetration in human lung tissue after hyperthermic exposure. Eur J Cardiothorac Surg 2015;47:563-6.

16 Dindo D, Demartines N, Clavien P-A. Classification of surgical complications: a new proposal with evaluation in a cohort of 6336 patients and results of a survey. Ann Surg 2004;240:205-13.

17 Kerscher C, Ried M, Hofmann H-S, et al. Anaesthetic management of cytoreductive surgery followed by hyperthermic intrathoracic chemotherapy perfusion. J Cardiothorac Surg 2014;9:125.

18 Refaely Y, Simansky DA, Paley M, et al. Resection and perfusion thermochemotherapy: a new approach for the treatment of thymic malignancies with pleural spread. Ann Thorac Surg 2001;72:366-70.

19 Yu L, Jing Y, Ma S, et al. Cytoreductive surgery combined with hyperthermic intrapleural chemotherapy to treat thymoma or thymic carcinoma with pleural dissemination. Onco Targets Ther 2013;6:517-21.

20 Ambrogi MC, Korasidis S, Lucchi M, et al. Pleural recurrence of thymoma: surgical resection followed by hyperthermic intrathoracic perfusion chemotherapy†. Eur J Cardiothorac Surg 2016;49:321-6.

21 Ried M, Potzger T, Braune N, et al. Local and systemic exposure of cisplatin during hyperthermic intrathoracic chemotherapy perfusion after pleurectomy and decortication for treatment of pleural malignancies. J Surg Oncol 2013;107:735-40.

22 Markowiak T, Kerner N, Neu R, et al. Adequate nephroprotection reduces renal complications after hyperthermic intrathoracic chemotherapy. J Surg Oncol 2019;120:1220-6. 
23 Ardizzoni A, Rosso R, Salvati F, et al. Activity of doxorubicin and cisplatin combination chemotherapy in patients with diffuse malignant pleural mesothelioma. an Italian lung cancer Task force (FONICAP) phase II study. Cancer 1991;67:2984-7.

24 Schmitt J, Loehrer PJ. The role of chemotherapy in advanced thymoma. J Thorac Oncol 2010;5:S357-60.

25 Maury JM, Girard N, Tabutin M, et al. Intra-Thoracic ChemoHyperthermia for pleural recurrence of thymoma. Lung Cancer 2017;108:1-6.

26 Yellin A, Simansky DA, Ben-Avi R, et al. Resection and heated pleural chemoperfusion in patients with thymic epithelial malignant disease and pleural spread: a single-institution experience. $J$ Thorac Cardiovasc Surg 2013;145:83-9.
27 Ishibashi H, Kobayashi M, Takasaki C, et al. Interim results of pleurectomy/decortication and intraoperative intrapleural hyperthermic cisplatin perfusion for patients with malignant pleural mesothelioma intolerable to extrapleural pneumonectomy. Gen Thorac Cardiovasc Surg 2015;63:395-400.

28 de Bree E, van Ruth S, Schotborgh CE, et al. Limited cardiotoxicity after extensive thoracic surgery and intraoperative hyperthermic intrathoracic chemotherapy with doxorubicin and cisplatin. Ann Surg Oncol 2007;14:3019-26.

29 Mustafa KY, Selig WM, Burhop KE, et al. Hyperthermia-Induced pulmonary edema. J Appl Physiol 1986;60:1980-5.

30 Bertoglio $\mathrm{P}$, Ambrogi MC, Chella A, et al. Is less also better? A singleinstitution experience on treatment of early stage malignant pleural mesothelioma. Eur J Surg Oncol 2017;43:1365-71. 